\title{
Effects of acute carbohydrate ingestion on anaerobic exercise performance
}

\author{
Ben M. Krings ${ }^{1 *}\left(\mathbb{D}\right.$, Jaden A. Rountree ${ }^{1}$, Matthew J. McAllister ${ }^{1}$, Patrick M. Cummings ${ }^{1}$, Timothy J. Peterson ${ }^{1}$, \\ Brent J. Fountain ${ }^{2}$ and JohnEric W. Smith ${ }^{1}$
}

\begin{abstract}
Background: Carbohydrate $(\mathrm{CHO})$ supplementation during endurance exercises has been shown to increase performance, but there is limited research with $\mathrm{CHO}$ supplementation during strength and conditioning exercises. Therefore, the purpose of this study was to examine the effects of various levels of $\mathrm{CHO}$ ingestion during acute testing sessions requiring participants to complete a strength and conditioning program designed for collegiate athletes.
\end{abstract}

Methods: Participants $(n=7)$ performed a series of exercises while ingesting an amino-acid electrolyte control (CON) or CON plus varying levels of $\mathrm{CHO}$. The $\mathrm{CHO}$ beverages delivered a 2:1 (glucose: fructose) ratio at rates of $15 \mathrm{~g} / \mathrm{h}$, $30 \mathrm{~g} / \mathrm{h}$, and $60 \mathrm{~g} / \mathrm{h}$. The exercise protocol consisted of a series of short sprints, full body resistance training exercises, jumping, and shuttle running. Performance measurements were taken for sprint times, repetitions until failure [bench press, bent over row, biceps curl, overhead triceps extension], summation of total repetitions for all repetitions until failure, repetitions in a set time for two-foot line jumps, and 137-m shuttle times.

Results: A significant main effect $(p<0.05)$ was found in relation to $\mathrm{CHO}$ dose during the bench press final set repetitions to failure. Pairwise comparison with Bonferroni's correction identified that there was significant difference ( $p=0.0024)$ between the dosage of $15 \mathrm{~g} / \mathrm{h}$ and CON during bench press. Inferential statistics identified overall RT performance with a dosage of $15 \mathrm{~g} / \mathrm{h}$ compared to $60 \mathrm{~g} / \mathrm{h}$ and CON was $99.2 \%$ (very likely) and $96.7 \%$ (very likely) to have a beneficial effect.

Conclusions: The results from this study suggest acute ingestion of $\mathrm{CHO}$ does not result in decrements in performance and may provide a beneficial effect to strength and conditioning performance. Strength and conditioning coaches may recommend their athletes ingest $\mathrm{CHO}$ during training sessions in order to maximize muscular adaptations.

Keywords: Resistance Training, Conditioning, Sprinting, Jumping

\section{Background}

Ergogenic aids, including carbohydrate $(\mathrm{CHO})$, are popular means of supplementation for athletes of all sports with the goal of improving performance and recovery. Strength and conditioning programs vary depending on sport, but common practices implemented in Division 1 athletics include the use of a periodization protocol, utilization of multiple sets, plyometrics training, explosive movements, and Olympic lifts [1]. While a great deal of

\footnotetext{
*Correspondence: bmk216@msstate.edu

'Department of Kinesiology, Mississippi State University, Mississippi State, MS 39762, USA

Full list of author information is available at the end of the article
}

research has investigated the role of $\mathrm{CHO}$ in endurance sports, $\mathrm{CHO}$ supplementation with resistance training (RT) has received less focus. The efficacy of CHO supplementation with a training regimen typical of full strength and conditioning sessions has received even less attention. Considering the minimal time strength and conditioning coaches are allowed to train athletes during both offseason and in-season, any enhancement of the time utilization is beneficial.

Resistance training is a large component of strength and conditioning sessions. During RT sessions requiring multiple sets with various exercises, it has been shown that muscle glycogen becomes a major fuel substrate, 
especially during high intensity practices. Haff et al. [2] reported a $40 \%$ decrease in muscle glycogen stores in the vastus lateralis immediately following $39 \mathrm{~min}$ of lower body isokinetic and free-weight exercise. The results from this study are similar to other studies that have found significant decreases in lower body muscle glycogen stores following acute bouts of RT [3, 4]. Research examining performance with $\mathrm{RT}$ and $\mathrm{CHO}$ supplementation have shown mixed results. Haff et al. [5] reported an increase in squat performance to exhaustion during a second training sessions in the same day with $\mathrm{CHO}$ supplementation before, during, and after RT. Other studies have found similar increases in performance during lower body leg exercises with $\mathrm{CHO}$ supplemented before and during exercises [6-9]. Opposing studies have shown no increases in muscular performance following $\mathrm{CHO}$ supplementation before and during exercise $[2,10,11]$. These contrasting results may be related to exercise protocol, target muscle groups, and overall length of training sessions. Along with possibly increasing performance during training sessions, $\mathrm{CHO}$ supplementation has been shown to increase insulin levels $[12,13]$ and suppress protein degradation [14], increasing the anabolic environment following RT. In combination with the possibility of an acute increase in performance, $\mathrm{CHO}$ supplementation may provide favorable hormonal adaptations following RT.

Although RT is an important component of strength and conditioning, other facets of training such as sprints, jumps, plyometric training, and conditioning should not be overlooked. Improvements in vertical jump performance has been shown when participants are supplemented with $\mathrm{CHO}$ and required to repeat maximal vertical jumps $[15,16]$. Contrast to the results of these published studies, results from other studies have shown $\mathrm{CHO}$ supplementation to have no effect on vertical jump performance [17-19]. Speed is often used as a marker for athletic success, as faster athletes tend to have greater success [20-22]. Carbohydrate supplementation and sprint performance research has shown mixed results. During soccer specific training games, a 6.4 and $6.2 \% \mathrm{CHO}$ solution has been shown to significantly decrease sprint time [23, 24]. When examining sprint performance during other athletic events such as simulated basketball activities, a $6 \% \mathrm{CHO}$ solution was shown to have no performance increases $[17,18]$. With varying results on sprinting and jumping performance, more research is needed to establish the efficacy of $\mathrm{CHO}$ supplementation during these types of activities.

An important component of $\mathrm{CHO}$ supplementation is to provide optimal dosages to elicit the greatest possible ergogenic effect. The majority of $\mathrm{CHO}$ dose response research has been focused on endurance performance. Smith et al. [25] suggests when glucose is ingested at a rate of $15 \mathrm{~g} / \mathrm{h}$ to $60 \mathrm{~g} / \mathrm{h}$ during endurance exercise lasting $150 \mathrm{~min}$, there is a dose-performance relationship. The optimal dosage for non-endurance activities has not been established. Studies that have shown increases in performance with $\mathrm{CHO}$ supplementation and RT have utilized dosages from 10 to $20 \%$ CHO solutions [5-9] however most commerically available sports beverages are $2-8 \%$ carbohydrate. Identifying a possible doseperformance relationship during strength and conditioning practices is an area that has received minimal research and is an important aspect in establishing the value of CHO supplementation.

Based on the current body of scientific literature, $\mathrm{CHO}$ supplementation with RT, jumps, and sprints have shown conflicting results. Athletes participating in multiple modes of training combined into one protocol may benefit from $\mathrm{CHO}$ supplementation by attenuating muscle glycogen depletion along with increasing performance. Therefore, the purpose of this investigation was to examine the effects of various levels of $\mathrm{CHO}$ supplementation during acute testing sessions that requires participants to complete a series of jumps, sprints, RT exercises, and shuttle runs.

\section{Methods}

\section{Experimental design}

The present investigation used a double-blinded, randomized, and crossover design to examine the effects of amino-acid electrolyte control (CON), in addition to $\mathrm{CON}$ plus varying concentrations of $\mathrm{CHO}$ which consisted of either $15 \mathrm{~g} / \mathrm{h}, 30 \mathrm{~g} / \mathrm{h}$, or $60 \mathrm{~g} / \mathrm{h}$ on athletic performance. The experimental period consisted of six sessions. All participants reported to the University Recreation Center following at least a $10 \mathrm{~h}$ fast at either 6:00, 7:30, or 9:00 AM. The first session was used to determine participants' height (Shorrboard Measuring Device, Weigh and Measure LLC., Olney, Maryland, USA), body mass (Ironman Innerscan, Tanita, Arlington, Illinois, USA), one repetition-maximum (1-RM) of RT exercises, and familiarize participants with the protocol. The second training session served as a familiarization session with no supplementation. During testing sessions three through six, participants completed a strength and conditioning protocol while consuming either $\mathrm{CON}$, $\mathrm{CON}+15 \mathrm{~g} / \mathrm{h}, \mathrm{CON}+30 \mathrm{~g} / \mathrm{h}$, and $\mathrm{CON}+60 \mathrm{~g} / \mathrm{h}$ at a 2:1 (glucose: fructose) ratio in beverage form. Participants received seven to 10 days between supplementation sessions three through six to allow for proper recovery time. During the course of the study, participants were instructed to refrain from exercising $24 \mathrm{~h}$ prior to sessions, but were advised to keep their normal exercise routine throughout the study and maintain normal sleep and dietary habits. 


\section{Participants}

A total of nine highly trained males volunteered to participate in the study; however, two participants withdrew during the course of the study. Therefore, data are reported for seven participants (mean $\pm \mathrm{SD}$; age $21.9 \pm 1.6$ years, body mass $91.6 \pm 9.7 \mathrm{~kg}$, height $181.2 \pm 5.8 \mathrm{~cm}$ ). Average daily dietary intakes during the course of data collection for participants is as follows: mean $\pm \mathrm{SD}$; kcal intake $2922 \pm 527$ kcals; $\mathrm{CHO} 46 \pm 11 \%$; protein $30 \pm 12 \%$; fat $26 \pm 4 \%$. Participant inclusion criteria were as follows: (1) meet advanced level of training according to the NSCA standards [26], (2) have experience with performing hang clean and front squat exercises. In order to meet the advanced level of training according to the NSCA, participants had to have a training age of $\geq 1$ year, training frequency of $\geq 3-4$ days per week, high degree of training stress, and high degree of technique experience and skill [26]. All participants gave informed consent and completed a PAR-Q and general health history questionnaire in accordance with the University Institutional Review Board approval before data collection.

\section{Experimental procedures}

\section{One-repetition maximum strength testing}

Maximal strength was assessed for each RT exercise by completing a predicted 1-RM test according to NSCA guidelines [26]. A total of three sets were completed for each exercise. During the first set, participants were instructed to use a weight corresponding with $50 \% 1$-RM for 5-10 repetitions. Following the first set and one minute of rest, participants completed a second set for 5-10 repetitions corresponding to 65-80 \% 1-RM. Participants rested one minute and commenced their third and final set. During the third set, participants were instructed to perform repetitions to failure in the full exercise range of motion for 4-8 repetitions. Between each exercise participants received two minutes of rest. Load and repetitions from the final set were used to estimate 1-RM through the following formula [27]: Estimated 1-RM = Weight lifted/ (1.0278-0.278 x reps).

\section{Supplementation}

Participants consumed either CON, CON $+15 \mathrm{~g} / \mathrm{h}$, $\mathrm{CON}+30 \mathrm{~g} / \mathrm{h}$, and $\mathrm{CON}+60 \mathrm{~g} / \mathrm{h}$ prior to exercise, and approximately every $15 \mathrm{~min}$ during exercise for a total of five ingestions. Since participants vary by the speed and time to complete jumps, sprints, and RT exercises, supplementation was given after specific exercises rather than on the exact 15 min marks. Total volume of each beverage was $118 \mathrm{~mL}$ and total volume consumed over the course each training session was $590 \mathrm{~mL}$. Participants were only allowed to drink supplemented beverages during testing sessions. The CON treatment consisted of amino acid-electrolyte beverage mixture of
1.25 g L-Leucine, 0.625 g L-Isoleucine, 0.625 g L-Valine, 2 g L-Taurine, $1 \mathrm{~g}$ L-Citrulline with each serving (Dymatize Enterprises, LLC., Dallas, TX, USA). The $\mathrm{CHO}$ beverages consisted of $\mathrm{CON}$ in addition to 2:1 part (glucose:fructose) ratio consisting of delivering either $15 \mathrm{~g} / \mathrm{h}, 30 \mathrm{~g} / \mathrm{h}$, or $60 \mathrm{~g} / \mathrm{h}$. These dosages correspond with a beverage mixture of 3,6 , and $12 \% \mathrm{CHO}$. These dosages were chosen because standard sports drinks range from 6 to $8 \% \mathrm{CHO}$ and lower calorie produces designed for exercise occasions typically range from 2 to $3 \%$ $\mathrm{CHO}$. All treatments were manufactured by Dymatize Enterprises, LLC. The treatments were sent to a researcher who prepared beverages for the study and was excluded to all data collection and analysis. All beverages were delivered in an opaque bottle with indistinguishable flavor, taste, and color between $\mathrm{CHO}$ and $\mathrm{CON}$ treatments. Consumption of all treatments throughout the study were witnessed by the principal investigator to ensure participant compliance.

\section{Testing protocol}

Following a standardized dynamic warm-up, participants completed a supervised testing protocol (Table 1). The strength and conditioning protocol was designed by a Division 1 strength and conditioning coach to simulate a collegiate football training session. The overall time it took participants to complete the training protocol was $71.3 \pm 2.9 \mathrm{~min}$. Immediately following a dynamic warmup, participants received the first beverage and began the protocol. During the speed work portion of the protocol, participants were instructed to jump and sprint with maximal effort. Max broad jump distance was measured and recorded in centimeters using a measuring tape (Martin Sports, Inc., Carlstedt, New Jersey, USA). All sprint exercises were electronically timed (Test Center Timing System, Brower Timing Systems, Draper, Utah, USA). Following the completion of the second 27-m sprint, the second beverage was administered and participants received two minutes of rest. Resistance training exercises were completed using the same percentage of weight based off of individual 1-RM for sessions two through six. The exercises of dumbbell (DB) bench press and barbell $(\mathrm{BB})$ bent-over row were completed as a superset as was DB biceps curl and DB overhead triceps extension. During the final set of these four exercises, participants were instructed to complete as many repetitions as possible until muscular failure. The third beverage was consumed following the fifth set of front squats, the fourth was ingested following BB bent over row, and the fifth was consumed after completing DB overhead triceps extension. Following this exercise, two minutes of rest was allowed before completing the final two exercises. Performance variables used for data collection included max broad jump distance, 9-m sprint time, 18-m sprint time, 
Table 1 Training protocol

\begin{tabular}{|c|c|c|c|c|}
\hline Exercise & Intensity & Sets & Reps & Followed by seconds of rest \\
\hline \multicolumn{5}{|l|}{ Speed Work } \\
\hline Max Broad Jump & Max & 5 & 1 & $30 \mathrm{~s}$ between reps \\
\hline Broad Jump + 9-m Sprint & Max & 4 & 1 & $45 \mathrm{~s}$ between reps \\
\hline Overhead Medicine Ball Toss + 18-m Sprint & Max & 4 & 1 & $60 \mathrm{~s}$ between reps \\
\hline 27-m Sprint & Max & 2 & 1 & $60 \mathrm{~s}$ between reps \\
\hline \multicolumn{5}{|l|}{ Resistance Training } \\
\hline \multicolumn{5}{|l|}{ Hang Clean } \\
\hline & $50 \%-$ Max & 1 & 5 & $60 \mathrm{~s}$ between sets \\
\hline & $55 \%-$ Max & 1 & 4 & $60 \mathrm{~s}$ between sets \\
\hline & $60 \%-$ Max & 1 & 4 & $60 \mathrm{~s}$ between sets \\
\hline & $65 \%-$ Max & 1 & 4 & $60 \mathrm{~s}$ between sets \\
\hline & $70 \%-$ Max & 1 & 4 & $60 \mathrm{~s}$ between sets \\
\hline \multicolumn{5}{|l|}{ Front Squat/Box Jump } \\
\hline & $45 \%-$ Max & 1 & 8 & $60 \mathrm{~s}$ between sets \\
\hline & $65 \%-$ Max & 1 & 5 & $30 \mathrm{~s}$ between sets \\
\hline & 24" Box Jump & 1 & 5 & $90 \mathrm{~s}$ between sets \\
\hline & $70 \%-$ Max & 1 & 5 & $30 \mathrm{~s}$ between sets \\
\hline & 24" Box Jump & 1 & 5 & $90 \mathrm{~s}$ between sets \\
\hline & $80 \%-$ Max & 1 & 3 & $30 \mathrm{~s}$ between sets \\
\hline & 24" Box Jump & 1 & 5 & $90 \mathrm{~s}$ between sets \\
\hline & $85 \%$ - Max & 1 & 3 & $150 \mathrm{~s}$ between sets \\
\hline & $90 \%-$ Max & 1 & 2 & $150 \mathrm{~s}$ between sets \\
\hline & $60 \%-$ Max & 1 & 8 & $180 \mathrm{~s}$ between sets \\
\hline \multicolumn{5}{|l|}{ Dumbbell Bench Press } \\
\hline & $60 \%-$ Max & 1 & 10 & $60 \mathrm{~s}$ between sets \\
\hline & $65 \%-$ Max & 1 & 10 & $60 \mathrm{~s}$ between sets \\
\hline & $70 \%$ - Max & 1 & 10 & $60 \mathrm{~s}$ between sets \\
\hline & $73 \%$ - Max & 1 & Failure & $60 \mathrm{~s}$ between sets \\
\hline \multicolumn{5}{|l|}{ Barbell Bent-Over Row } \\
\hline & $60 \%-\operatorname{Max}$ & 1 & 10 & $60 \mathrm{~s}$ between sets \\
\hline & $65 \%-$ Max & 1 & 10 & $60 \mathrm{~s}$ between sets \\
\hline & $70 \%$ - Max & 1 & 10 & $60 \mathrm{~s}$ between sets \\
\hline & $73 \%$ - Max & 1 & Failure & $60 \mathrm{~s}$ between sets \\
\hline \multicolumn{5}{|l|}{ Barbell Reverse Lunge with Front Squat Grip } \\
\hline & $55 \%-$ Max & 2 & 12 & $30 \mathrm{~s}$ between sets \\
\hline & $65 \%-$ Max & 2 & 12 & $30 \mathrm{~s}$ between sets \\
\hline & $70 \%-$ Max & 2 & 12 & $30 \mathrm{~s}$ between sets \\
\hline \multicolumn{5}{|l|}{ Single Arm Shoulder Press } \\
\hline & $65 \%-$ Max & 2 & 10 & $30 \mathrm{~s}$ between sets \\
\hline & $70 \%-$ Max & 2 & 10 & $30 \mathrm{~s}$ between sets \\
\hline \multicolumn{5}{|l|}{ Dumbbell Biceps Curl } \\
\hline & $60 \%-$ Max & 2 & 10 & $45 \mathrm{~s}$ between sets \\
\hline & $60 \%-\operatorname{Max}$ & 1 & Failure & $45 \mathrm{~s}$ between sets \\
\hline
\end{tabular}


Table 1 Training protocol (Continued)

\begin{tabular}{lllll}
\hline Dumbbell Overhead Triceps Extension & & & \\
& $60 \%-$ Max & 2 & 10 & 45 s between sets \\
& $60 \%-$ Max & 1 & Failure & 45 s between sets \\
Agility/Shuttle Runs & & & $10 \mathrm{~s}$ & $45 \mathrm{~s}$ between sets \\
Two Foot Line Jumps & Max & 3 & 1 & 30 s between sets \\
$137-m$ shuttle & Max & 1 & 1 & 120 s between sets \\
$137-m$ shuttle & Max & 2 & 1 &
\end{tabular}

27-m sprint time, DB bench press, BB bent-over row, DB biceps curl, and DB overhead triceps extension final set repetitions, summation of total repetitions until muscular failure, repetitions in a set time for two-foot line jumps, and $137-\mathrm{m}$ shuttle times. All trials were supervised by a NSCA Certified Strength and Conditioning Specialist to ensure exercises were completed with proper form and safety.

\section{Statistical analysis}

Data are presented as mean \pm standard deviation. A significant alpha level was defined as $p<0.05$. Data were analyzed using SAS version 9.4 (SAS Institute, Cary, NC, USA). Performance variables were analyzed using repeated measures analysis of variance (ANOVA). When significant main effects were found, a Tukey Post-Hoc was performed with a Bonferroni correction to further investigate differences and to compare means between doses.

Prior to beginning data collection, the decision was made to also analyze the data using inferential statistics. To allow for the use of inferential statistics, meaningful effect based inferences as described by Hopkins et al. [28], pairwise t-tests were performed comparing individual dosages. A probabilistic magnitude-based inferential analysis was conducted with each comparison to determine the likelihood of a performance enhancement between $\mathrm{CHO}$ ingestion rates. Based on data reported by Hopkins et al. [29] that the smallest meaningful effects in athletes is $\sim 0.3-0.7$ of the coefficient of variation, this study used 0.5 of the coefficient of variation as the smallest meaningful improvement. Confidence intervals of $90 \%$ defined the uncertainty of the measure. The qualitative descriptions describing the chances the findings are larger than the smallest meaningful effect $(0.5 \mathrm{X}$ coefficient of variation) are: $<0.5 \%$, most unlikely or almost certainly not; $0.5-5 \%$, very unlikely; $5-25 \%$, unlikely or probably not; $25-75 \%$, possibly; 75-95 \%, likely or probably; $95-99.5 \%$, very likely; > $99.5 \%$, most likely or almost certainly [30].

Intraclass correlation coefficients (ICC) were calculated to predict reliability for all dependent variables. McGraw and Wong [31] model $(1, \mathrm{k})$ was used to calculate ICC. Cohen's effect size and sample size needed for a magnitude-based inference about the practical significance of the observed changes in performance for a power of $80 \%$ were also calculated.

\section{Results}

A significant main effect was found in relation to $\mathrm{CHO}$ dose during the DB bench press final set to failure. All carbohydrate treatments improved performance in comparison to the non-carbohydrate $\mathrm{CON}$ during $\mathrm{DB}$ bench press. However, after a Bonferroni correction the comparison of CON to $15 \mathrm{~g} / \mathrm{h}$ was the only comparison that was significantly different $(p=0.0024)$. The pairwise t-tests (conducted for between treatments for meaningful effect inferences) demonstrated a significant improvement in performance when $60 \mathrm{~g} / \mathrm{h}$ was consumed during the $27-\mathrm{m}$ sprint as compared to CON. Additionally, these pairwise $\mathrm{t}$-tests demonstrated $15 \mathrm{~g} / \mathrm{h}$ resulted in significant improvements in performance in summation of total repetitions performed as compared to $60 \mathrm{~g} / \mathrm{h}$.

Table 2 presents results from DB bench press, BB bent-over row, biceps curl, and overhead triceps extension. When compared to the $\mathrm{CON}$, all three $\mathrm{CHO}$ dosages significantly improved performance (Table 2) during DB bench press. However, a $95 \%$ likelihood for performance improvement was seen with $15 \mathrm{~g} / \mathrm{h}$ compared to $60 \mathrm{~g} / \mathrm{h}$. During BB bent-over row, $15 \mathrm{~g} / \mathrm{h}$ and $30 \mathrm{~g} / \mathrm{h}$ demonstrated a likely improvement in performance compared to both CON and $60 \mathrm{~g} / \mathrm{h}$. The dosage of $30 \mathrm{~g} / \mathrm{h}$ yielded the greatest performance during biceps curl. Chances of an increase in performance were very likely (95.4\%). Performance was shown to likely decrease when comparing $60 \mathrm{~g} / \mathrm{h}$ to $30 \mathrm{~g} / \mathrm{h}(-94.7 \%)$. Inferential statistics demonstrate minimal increases in performance with all three dosages during overhead triceps extension.

A summation of total repetitions from all RT exercises is presented in Table 3 . The dosage of $15 \mathrm{~g} / \mathrm{h}$ had the greatest performance when compared to CON (96.7\%, very likely), and approached significance $(p=0.06)$ with the pairwise t-tests used during inferential analysis. Performance with $60 \mathrm{~g} / \mathrm{h}$ was significantly lower $(p=0.01)$ than $15 \mathrm{~g} / \mathrm{h}$ with the same t-tests. Inferences suggest 
Table 2 Performance during resistance training exercises

\begin{tabular}{|c|c|c|c|c|c|}
\hline & & Total reps & $15 \mathrm{~g} / \mathrm{h}$ & $30 \mathrm{~g} / \mathrm{h}$ & $60 \mathrm{~g} / \mathrm{h}$ \\
\hline \multirow[t]{4}{*}{ Bench Press } & CON & $9.7 \pm 2.9$ & $\begin{array}{l}27.9 \% ; 1.3 \text { to } 4.1(0.83) \\
99.4 \% \text {, very likely (4) } \\
p=0.01\end{array}$ & $\begin{array}{l}20.6 \% ; 0.7 \text { to } 3.3(0.72) \\
98.2 \% \text {, very likely (6) } \\
p=0.03\end{array}$ & $\begin{array}{l}20.6 \% ; 0.5 \text { to } 3.5(0.66) \\
97.5 \% \text {, very likely (7) } \\
p=0.04\end{array}$ \\
\hline & $15 \mathrm{~g} / \mathrm{h}$ & $12.4 \pm 3.6$ & & $\begin{array}{l}-5.8 \% ;-2.0 \text { to } 0.6(0.22) \\
78.9 \% \text {, likely (63) } \\
p=0.33\end{array}$ & $\begin{array}{l}-5.8 \% ;-1.3 \text { to }-0.2(0.21) \\
-95.5 \% \text {, very likely (7) } \\
p=0.05\end{array}$ \\
\hline & $30 \mathrm{~g} / \mathrm{h}$ & $11.7 \pm 2.7$ & & & $\begin{array}{l}\text { No differences } \\
\mathrm{n} / \mathrm{a} \\
p=1.00\end{array}$ \\
\hline & $60 \mathrm{~g} / \mathrm{h}$ & $11.7 \pm 3.2$ & & & \\
\hline \multirow[t]{4}{*}{ Bent-Over Row } & CON & $16.6 \pm 5.3$ & $\begin{array}{l}6.9 \% ;-2.6 \text { to } 4.9(0.18) \\
68.4 \%, \text { possibly }(157) \\
p=0.57\end{array}$ & $\begin{array}{l}6.0 \% ;-1.28 \text { to } 3.8(0.20) \\
71.5 \% \text {, possibly }(108) \\
p=0.51\end{array}$ & $\begin{array}{l}-7.7 \% ;-3.3 \text { to } 0.7(0.28) \\
-84.9 \% \text {, likely }(35) \\
p=0.25\end{array}$ \\
\hline & $15 \mathrm{~g} / \mathrm{h}$ & $17.7 \pm 7.2$ & & $\begin{array}{l}-0.8 \% ;-3.7 \text { to } 3.4(0.02) \\
43.5 \% \text {, possibly }(30886) \\
p=0.94\end{array}$ & $\begin{array}{l}-13.7 \% ;-6.3 \text { to } 1.4(0.42) \\
-85.0 \% \text {, likely }(24) \\
p=0.27\end{array}$ \\
\hline & $30 \mathrm{~g} / \mathrm{h}$ & $17.6 \pm 4.5$ & & & $\begin{array}{l}-13.0 \% ;-4.2 \text { to }-0.31(0.56) \\
-96.1 \% \text {, very likely }(9) \\
p=0.07\end{array}$ \\
\hline & $60 \mathrm{~g} / \mathrm{h}$ & $15.3 \pm 3.7$ & & & \\
\hline \multirow[t]{4}{*}{ Biceps Curl } & CON & $12.3 \pm 4.9$ & $\begin{array}{l}3.5 \% ;-0.8 \text { to } 1.7(0.09) \\
64.0 \% \text {, possibly }(528) \\
p=0.53\end{array}$ & $\begin{array}{l}16.3 \% ; 0.3 \text { to } 3.8(0.37) \\
95.4 \% \text {, very likely }(10) \\
p=0.07\end{array}$ & $\begin{array}{l}-5.8 \% ;-2.3 \text { to } 0.9(0.15) \\
16.0 \% \text {, unlikely }(157) \\
p=0.43\end{array}$ \\
\hline & $15 \mathrm{~g} / \mathrm{h}$ & $12.7 \pm 4.8$ & & $\begin{array}{l}-12.4 \% ;-1.1 \text { to } 4.3(0.29) \\
82.0 \% \text {, likely (39) } \\
p=0.30\end{array}$ & $\begin{array}{l}-9.0 \% ;-2.9 \text { to } 0.6(0.24) \\
-84.0 \% \text {, likely }(41) \\
p=0.24\end{array}$ \\
\hline & $30 \mathrm{~g} / \mathrm{h}$ & $14.3 \pm 5.9$ & & & $\begin{array}{l}-19.0 \% ;-5.8 \text { to }-0.14(0.52) \\
-94.7 \% \text {, likely }(11) \\
p=0.09\end{array}$ \\
\hline & $60 \mathrm{~g} / \mathrm{h}$ & $11.6 \pm 4.6$ & & & \\
\hline \multirow[t]{4}{*}{ Overhead Triceps Extension } & CON & $13.7 \pm 4.5$ & $\begin{array}{l}7.3 \% ;-1.1 \text { to } 3.1(0.21) \\
76.3 \% \text {, likely (80) } \\
p=0.39\end{array}$ & $\begin{array}{l}2.1 \% ;-2.0 \text { to } 2.5(0.07) \\
54.5 \% \text {, possibly }(1659) \\
p=0.81\end{array}$ & $\begin{array}{l}-1.0 \% ;-2.0 \text { to } 1.7(0.03) \\
37.0 \%, \text { possibly }(10992) \\
p=0.88\end{array}$ \\
\hline & $15 \mathrm{~g} / \mathrm{h}$ & $14.7 \pm 5.2$ & & $\begin{array}{l}-4.9 \% ;-3.6 \text { to } 2.2(0.15) \\
28.8 \%, \text { possibly }(261) \\
p=0.65\end{array}$ & $\begin{array}{l}-4.9 \% ;-3.6 \text { to } 2.2(0.15) \\
28.8 \% \text {, possibly }(261) \\
p=0.65\end{array}$ \\
\hline & $30 \mathrm{~g} / \mathrm{h}$ & $14.0 \pm 4.2$ & & & $\begin{array}{l}-3.1 \% ;-3.8 \text { to } 3.0(0.08) \\
37.13 \%, \text { possibly }(1308) \\
p=0.82\end{array}$ \\
\hline & $60 \mathrm{~g} / \mathrm{h}$ & $13.6 \pm 5.8$ & & & \\
\hline
\end{tabular}

Data indicate total repetitions for all RT exercises with ingestion of 15, 30, and $60 \mathrm{~g} / \mathrm{h}$ of 2:1 glucose: fructose (mean total repetitions \pm SD) and \%improvement in total repetitions [1st line: \%improvement, $90 \%$ confidence interval limits, and Cohen's effect size (ES; in parentheses); 2nd line: chances (\% and qualitative) of meaningful improvement $(>0.5 \% \mathrm{CV})$ and sample size needed for a magnitude-based inference about the practical significance of the observed changes in performance for a power of $80 \%$ (in parentheses); 3rd line: exact $P$ value from pairwise t-tests]

that $15 \mathrm{~g} / \mathrm{h}$ is $99.2 \%$ (very likely) to improve performance compared to $60 \mathrm{~g} / \mathrm{h}$. CHO supplementation of $30 \mathrm{~g} / \mathrm{h}$ had the likelihood to improve performance when compared to $\mathrm{CON}$, and $60 \mathrm{~g} / \mathrm{h}$ was likely to negatively impact performance when compared to $30 \mathrm{~g} / \mathrm{h}$. Dosage rates of $15 \mathrm{~g} / \mathrm{h}$ and $30 \mathrm{~g} / \mathrm{h}$ had the greatest likelihood to improve performance when repetitions from DB bench press, BB bent-over row, biceps curl, and overhead triceps extension were summated.

Performance during sprints and shuttle runs is represented in Table 4. Using the pairwise t-tests for inferential statistics, there was significant reduction in sprint time ( $p=0.04$ ), with $60 \mathrm{~g} / \mathrm{h}$ compared to CON during 27-m sprint time. The significant reduction in sprint time at $60 \mathrm{~g} / \mathrm{h}$ corresponds with a very likely (96 \%) increase in performance. At a dosage of $30 \mathrm{~g} / \mathrm{h}$, performance was likely to improve, compared to CON. During $18-\mathrm{m}$ sprints, $60 \mathrm{~g} / \mathrm{h}$ was the only dosage to have a likelihood to improve performance when compared to CON. Performance did not improve at all three dosages when compared to CON during 9-m sprints. A dosage of $30 \mathrm{~g} / \mathrm{h}$ was likely $(90.1 \%)$ to improve $127-\mathrm{m}$ shuttle performance when 
Table 3 Total repetitions performance

\begin{tabular}{|c|c|c|c|c|c|}
\hline & & Total reps & $15 \mathrm{~g} / \mathrm{h}$ & $30 \mathrm{~g} / \mathrm{h}$ & $60 \mathrm{~g} / \mathrm{h}$ \\
\hline \multirow[t]{3}{*}{ Total Repetitions } & $\mathrm{CON}$ & $52.3 \pm 14.2$ & $\begin{array}{l}10.1 \% ; 0.8 \text { to } 9.8(0.42) \\
96.7 \% \text {, very likely }(9) \\
p=0.06\end{array}$ & $\begin{array}{l}10.1 \% ;-1.2 \text { to } 11.8(0.39) \\
91.2 \% \text {, likely (19) } \\
p=0.17\end{array}$ & $\begin{array}{l}-0.3 \% ;-3.5 \text { to } 3.2(0.01) \\
44.1 \%, \text { possibly }(123526) \\
p=0.94\end{array}$ \\
\hline & $15 \mathrm{~g} / \mathrm{h}$ & $57.6 \pm 10.5$ & & $\begin{array}{l}\text { No differences } \\
\mathrm{n} / \mathrm{a} \\
p=1.00\end{array}$ & $\begin{array}{l}-9.4 \% ;-8.5 \text { to }-2.3(0.47) \\
-99.2 \% \text {, very likely (2) } \\
p=0.01\end{array}$ \\
\hline & $30 \mathrm{~g} / \mathrm{h}$ & $57.6 \pm 13.2$ & & & $\begin{array}{l}-9.4 \% ;-13.3 \text { to } 2.41(0.42) \\
-88.2 \% \text {, likely ( } 21) \\
p=0.23\end{array}$ \\
\hline
\end{tabular}

$60 \mathrm{~g} / \mathrm{h} \quad 52.1 \pm 12.6$

\begin{abstract}
Data indicate summation of total repetitions for all RT exercises with ingestion of 15, 30, and $60 \mathrm{~g} / \mathrm{h}$ of 2:1 glucose: fructose (mean total repetitions \pm SD) and \%improvement in total repetitions [1st line: \%improvement, 90 \% confidence interval limits, and Cohen's effect size (ES; in parentheses); 2nd line: chances (\% and qualitative) of meaningful improvement $(>0.5 \% \mathrm{CV})$ and sample size needed for a magnitude-based inference about the practical significance of the observed changes in performance for a power of $80 \%$ (in parentheses); $3^{\text {rd }}$ line: exact $P$ value from pairwise t-tests]
\end{abstract}

compared to $15 \mathrm{~g} / \mathrm{h}$. Inferences also suggest $30 \mathrm{~g} / \mathrm{h}$ has a likely $(76.4 \%)$ chance to improve performance compared to CON. Carbohydrate supplementation of $60 \mathrm{~g} / \mathrm{h}$ had the greatest performance during $27-\mathrm{m}$ and $18-\mathrm{m}$ sprints compared to $15 \mathrm{~g} / \mathrm{h}, 30 \mathrm{~g} / \mathrm{h}$, and $\mathrm{CON}$.

Table 5 represents performance during max broad jumps. The greatest likelihood to improve performance was seen when $60 \mathrm{~g} / \mathrm{h}(81.7 \%)$ was compared to $30 \mathrm{~g} / \mathrm{h}$. Performance was likely negatively impacted (-79.9\%) when comparing $30 \mathrm{~g} / \mathrm{h}$ to $15 \mathrm{~g} / \mathrm{h}$. Table 6 represents total touches during two-foot line jumps. All three $\mathrm{CHO}$ dosages were likely to improve performance compared to $\mathrm{CON}$.

Calculated ICC values for all dependent variable are as follows: DB bench press (0.72), BB bent-over row (0.89), overhead triceps extension (0.97), biceps curls (0.89), total repetitions (0.88), max broad jump (0.98), 9-m sprint (0.98), 18-m sprint (0.87), 27-m sprint (0.87), twofoot line jumps (0.95), and 137-m shuttle (0.96).

\section{Discussion}

Based on the combined findings of this study across strength and conditioning exercises, ingestion of $\mathrm{CHO}$ has a likelihood to improve performance compared to an amino-acid electrolyte beverage that did not contain $\mathrm{CHO}$. The likelihood of an amino-acid electrolyte beverage to lead to an acute improvement in performance as compared to a $\mathrm{CHO}$ containing beverage is small. Previous research has demonstrated no ergogenic effect with an amino-acid beverage compared to a placebo when completing a series of sprints, jumps, and resistance training exercises [32]. Findings from the present investigation show similar results compared to previous studies reporting improvements in $\mathrm{RT}$ performance with $\mathrm{CHO}$ supplementation [5-9]. Along with increases in bench press performance, magnitude based inferential statistical analysis found that $\mathrm{CHO}$ significantly increased 27-m sprint time and overall RT performance, measured by summation of total repetitions over the last set of each RT exercise. Based off of the results from both traditional statistics and magnitude based inferences, $\mathrm{CHO}$ supplementation demonstrated performance improvement during multiple aspects of a traditional collegiate strength and conditioning protocol.

Investigations reporting no increases in RT performance with $\mathrm{CHO}$ supplementation may be related to the inability to sensitively measure changes based off of repetition count, overall exercise protocol, $\mathrm{CHO}$ dosages, and exercise intensity. Kulik et al. [11] reported no increases with $\mathrm{CHO}$ during 5 sets of back squat at $85 \%$ 1-RM until exhaustion. The overall protocol lasted approximately $29 \mathrm{~min}$ compared to the present investigation length of a $71 \mathrm{~min}$. Other studies reporting similar findings, also employed shorter duration exercise protocols $[2,10]$. The longer duration of the present investigation may partially explain ergogenic effects of $\mathrm{CHO}$. It is well known that muscle glycogen depletion increases with prolonged and high intensity RT [3, 33-35]. As muscle glycogen depletes during a protocol that requires participants to complete RT exercise, maximal sprints, repeated maximal jumps, and shuttle runs, exogenous glucose may spare glycogenolysis and become a preferred fuel. A unique aspect of the RT protocol of the present investigation is the use of upper body exercise completed until muscular failure. A majority of previous research has been focused primarily on $\mathrm{CHO}$ supplementation to lower body exercises $[2,5-9,11]$. DB bench press was the only dependent measure that elicited a significant main effect and after a Bonferroni correction was applied, performance was significantly increased when $15 \mathrm{~g} / \mathrm{h}$ of $\mathrm{CHO}$ was administered compared to CON. Therefore, caution is warranted when making strong interpretations from these data. Although traditional statistics are common place in strength and conditioning research, the decision was made a priori to also analyze results using magnitude based inferential statistics. Due to the large percentage changes necessary to assess changes in performance through repetition 
Table 4 Performance during sprinting and shuttle runs

\begin{tabular}{|c|c|c|c|c|c|}
\hline & & Time (sec) & $15 \mathrm{~g} / \mathrm{h}$ & $30 \mathrm{~g} / \mathrm{h}$ & $60 \mathrm{~g} / \mathrm{h}$ \\
\hline \multirow[t]{4}{*}{ 27-m Sprints } & CON & $4.26 \pm 0.15$ & $\begin{array}{l}-0.3 \% ;-0.12 \text { to } 0.09(0.06) \\
42.9 \% \text {, possibly }(2374) \\
p=0.83\end{array}$ & $\begin{array}{l}-1.3 \% ;-0.14 \text { to } 0.03(0.42) \\
80.1 \% \text {, likely }(23) \\
p=0.25\end{array}$ & $\begin{array}{l}-1.9 \% ;-0.14 \text { to }-0.02(0.56) \\
96.0 \% \text {, very likely }(7) \\
p=0.04\end{array}$ \\
\hline & $15 \mathrm{~g} / \mathrm{h}$ & $4.25 \pm 0.24$ & & $\begin{array}{l}-1.0 \% ;-0.20 \text { to } 0.12(0.23) \\
60.2 \% \text {, possibly }(93) \\
p=0.62\end{array}$ & $\begin{array}{l}-1.7 \% ;-0.16 \text { to } 0.01(0.36) \\
84.5 \% \text {, likely }(19) \\
p=0.16\end{array}$ \\
\hline & $30 \mathrm{~g} / \mathrm{h}$ & $4.21 \pm 0.11$ & & & $\begin{array}{l}-0.7 ;-0.10 \text { to } 0.05(0.22) \\
62.6 \% \text {, likely }(98) \\
p=0.51\end{array}$ \\
\hline & $60 \mathrm{~g} / \mathrm{h}$ & $4.18 \pm 0.14$ & & & \\
\hline \multirow[t]{4}{*}{ 18-m Sprints } & CON & $2.95 \pm 0.09$ & $\begin{array}{l}0.2 \% ;-0.06 \text { to } 0.07(0.05) \\
23.4 \% \text {, unlikely }(1980) \\
p=0.86\end{array}$ & $\begin{array}{l}0.5 \% ;-0.09 \text { to } 0.12(0.12) \\
27.6 \% \text {, possibly }(662) \\
p=0.79\end{array}$ & $\begin{array}{l}-1.4 \% ;-0.10 \text { to } 0.02(0.48) \\
78.77 \% \text {, likely }(113) \\
p=0.23\end{array}$ \\
\hline & $15 \mathrm{~g} / \mathrm{h}$ & $2.96 \pm 0.15$ & & $\begin{array}{l}0.3 \% ;-0.12 \text { to } 0.14(0.06) \\
31.7 \% \text {, possibly }(3099) \\
p=0.90\end{array}$ & $\begin{array}{l}0.3 \% ;-0.11 \text { to } 0.13(0.06) \\
31.3 \%, \text { possibly }(3099) \\
p=0.90\end{array}$ \\
\hline & $30 \mathrm{~g} / \mathrm{h}$ & $2.97 \pm 0.14$ & & & $\begin{array}{l}-1.9 \% ;-0.14 \text { to } 0.03(0.49) \\
82.6 \% \text {, likely }(22) \\
p=0.23\end{array}$ \\
\hline & $60 \mathrm{~g} / \mathrm{h}$ & $2.91 \pm 0.08$ & & & \\
\hline \multirow[t]{4}{*}{ 9-m Sprints } & CON & $1.43 \pm 0.09$ & $\begin{array}{l}0.8 \% ;-0.03 \text { to } 0.05(0.14) \\
5.1 \% \text {, unlikely }(255) \\
p=0.58\end{array}$ & $\begin{array}{l}0.6 \% ;-0.02 \text { to } 0.03(0.11) \\
2.0 \% \text {, very unlikely }(358) \\
p=0.53\end{array}$ & $\begin{array}{l}0.2 \% ;-0.04 \text { to } 0.1(0.04) \\
16.8 \% \text {, unlikely }(6570) \\
p=0.90\end{array}$ \\
\hline & $15 \mathrm{~g} / \mathrm{h}$ & $1.44 \pm 0.08$ & & $\begin{array}{l}-0.2 \% ;-0.04 \text { to } 0.04(0.04) \\
11.3 \% \text {, unlikely }(6349) \\
p=0.89\end{array}$ & $\begin{array}{l}-0.6 \% ;-0.05 \text { to } 0.04(0.12) \\
26.9 \%, \text { possibly }(465) \\
p=0.72\end{array}$ \\
\hline & $30 \mathrm{~g} / \mathrm{h}$ & $1.44 \pm 0.07$ & & & $\begin{array}{l}-0.4 \% ;-0.03 \text { to } 0.02(.09) \\
12.0 \% \text {, unlikely }(696) \\
p=0.65\end{array}$ \\
\hline & $60 \mathrm{~g} / \mathrm{h}$ & $1.43 \pm 0.07$ & & & \\
\hline \multirow[t]{4}{*}{ 137-m Shuttle Runs } & CON & $39.8 \pm 4.01$ & $\begin{array}{l}-0.2 \% ;-2.0 \text { to } 1.8(0.03) \\
44.7 \% \text {, possibly }(13118) \\
p=0.93\end{array}$ & $\begin{array}{l}-2.3 \% ;-3.1 \text { to } 1.3(0.24) \\
76.4 \% \text {, likely }(74) \\
p=0.45\end{array}$ & $\begin{array}{l}-1.7 \% ;-3.0 \text { to } 2.4(0.19) \\
68.5 \% \text {, possibly }(155) \\
p=0.61\end{array}$ \\
\hline & $15 \mathrm{~g} / \mathrm{h}$ & $39.7 \pm 3.12$ & & $\begin{array}{l}-2.1 \% ;-1.9 \text { to } 0.2(0.24) \\
90.1 \% \text {, likely }(31) \\
p=0.18\end{array}$ & $\begin{array}{l}-1.4 \% ;-1.7 \text { to } 0.6(0.20) \\
80.1 \% \% \text {, likely }(82) \\
p=0.37\end{array}$ \\
\hline & $30 \mathrm{~g} / \mathrm{h}$ & $38.9 \pm 3.66$ & & & $\begin{array}{l}0.7 \% ;-0.9 \text { to } 1.4(0.08) \\
31.8 \% \text {, possibly }(936) \\
p=0.68\end{array}$ \\
\hline & $60 \mathrm{~g} / \mathrm{h}$ & $39.2 \pm 2.65$ & & & \\
\hline
\end{tabular}

Data indicate sprinting times with ingestion of 15,30 , and $60 \mathrm{~g} / \mathrm{h}$ of 2:1 glucose: fructose (mean total repetitions \pm SD) and \%improvement in sprinting time [1st line: \%improvement, $90 \%$ confidence interval limits, and Cohen's effect size (ES; in parentheses); 2 nd line: chances (\% and qualitative) of meaningful improvement ( $>0.5 \%$ CV) and sample size needed for a magnitude-based inference about the practical significance of the observed changes in performance for a power of $80 \%$ (in parentheses); $3^{\text {rd }}$ line: exact $P$ value from pairwise t-tests]

count based off of traditional statistical analyses alone, inferential statistics provide a meaningful interpretation to strength and conditioning coaches. Based off our results, we were able to determine that $\mathrm{CHO}$ ingestion overall appears to be more beneficial from an ergogenic standpoint. This is apparent especially since a small ergogenic effect may be smaller than what can be determined by traditional statistical analysis. Summation of total repetitions until failure with $15 \mathrm{~g} / \mathrm{h}$ of $\mathrm{CHO}$ compared to $60 \mathrm{~g} / \mathrm{h}$ and $\mathrm{CON}$ was $99.2 \%$ (very likely) and $96.7 \%$ (very likely) to have a beneficial effect, respectively. The greater physiological demands from the high intensity/volume full body exercise protocol may possibly explain the increase in performance during a final set until failure during DB bench press and overall summation of repetitions with $15 \mathrm{~g} / \mathrm{h}$ of $\mathrm{CHO}$. In addition, due to the overall protocol length, the ergogenic effect elicited to RT performance with exogenous $\mathrm{CHO}$ supplementation may be a product of volume completed within a training session.

Literature indicating decreases in sprint time during soccer specific drills $[23,24]$ and increases in jump height $[15,16]$ have employed varying exercise protocols, making 
Table 5 Performance during max broad jumps

\begin{tabular}{|c|c|c|c|c|c|}
\hline & & Average distance $(\mathrm{cm})$ & $15 \mathrm{~g} / \mathrm{h}$ & $30 \mathrm{~g} / \mathrm{h}$ & $60 \mathrm{~g} / \mathrm{h}$ \\
\hline \multirow[t]{4}{*}{ Max Broad Jumps } & $\mathrm{CON}$ & $246.2 \pm 29.7$ & $\begin{array}{l}1.0 \% ;-5.0 \text { to } 10.0(0.09) \\
72.3 \% \text {, possibly }(553) \\
p=0.55\end{array}$ & $\begin{array}{l}-1.2 \% ;-13.3 \text { to } 7.2(0.12) \\
28.8 \% \text {, possibly }(341) \\
p=0.58\end{array}$ & $\begin{array}{l}0.7 \% ;-8.7 \text { to } 12.1(0.06) \\
61.7 \% \text {, possibly }(1987) \\
p=0.76\end{array}$ \\
\hline & $15 \mathrm{~g} / \mathrm{h}$ & $248.7 \pm 26.6$ & & $\begin{array}{l}2.2 \% ;-17.4 \text { to } 6.3(0.22) \\
-79.9 \% \text {, (likely) (76) } \\
p=0.40\end{array}$ & $\begin{array}{l}-0.3 \% ;-9.8 \text { to } 8.3(0.03) \\
43.3 \% \text {, possibly }(10586) \\
p=0.87\end{array}$ \\
\hline & $30 \mathrm{~g} / \mathrm{h}$ & $243.2 \pm 22.6$ & & & $\begin{array}{l}2.0 \% \text {; }-4.6 \text { to } 14.2(0.21) \\
81.7 \% \text {, likely (74) } \\
p=0.68\end{array}$ \\
\hline & $60 \mathrm{~g} / \mathrm{h}$ & $247.2 \pm 29.7$ & & & \\
\hline
\end{tabular}

Data indicate max broad jump distance with ingestion of 15, 30, and $60 \mathrm{~g} / \mathrm{h}$ 2:1 glucose: fructose (mean total repetitions \pm SD) and \%improvement in jump distance [1st line: \%improvement, $90 \%$ confidence interval limits, and Cohen's effect size (ES; in parentheses); 2nd line: chances (\% and qualitative) of meaningful improvement $(>0.5 \% \mathrm{CV}$ ) and sample size needed for a magnitude-based inference about the practical significance of the observed changes in performance for a power of $80 \%$ (in parentheses); $3^{\text {rd }}$ line: exact $P$ value from pairwise $t$-test]

it is difficult to directly compare results of the present investigation to previous studies. In the current investigation, participants completed maximal jumps and short sprints within the first $15 \mathrm{~min}$ of the exercise protocol in which they only received one beverage. Inferential statistics suggested that a dosage of $60 \mathrm{~g} / \mathrm{h}$ significantly improved performance compared to CON during the $27-\mathrm{m}$ sprints. A possible method for a significant performance benefit from only supplementation of $60 \mathrm{~g} / \mathrm{h}$ may possibly be explained through the benefits of $\mathrm{CHO}$ mouth rinse. In a recent review, Jeukendrup and Chambers [36] indicate that $\mathrm{CHO}$ may improve performance through non metabolic means. The mechanisms include stimulation of the positive afferent signals, modifying motor output and increasing performance. The mouth rinse technique has been shown to increase performance during endurance activities [37-40], but to have no significant changes in performance when completing repeated sprints [41], muscular strength and muscular endurance [42, 43]. However, additional research with $\mathrm{CHO}$ mouth rinse during short duration maximal sprints, and jumps is needed to examine the possible ergogenic effects of $\mathrm{CHO}$ using this mechanism.

When comparing doses of $\mathrm{CHO}$, the separation on performance enhancement during a strength and conditioning protocol becomes difficult to discern. Performance was found to improve significantly for one exercise at a dose that it did not improve for another. A dose-performance relationship may exist during endurance exercise [25, 44], but results from the current investigation make it difficult to discern between dosages for strength and conditioning exercises. While not measured, this could possibly be explained due to the differing physical demands between exercises and potentially due to the ability of the gut to empty its contents versus increased beverage volumes remaining in the stomach or intestine.

There are several limitations to our study. Although average dietary intakes from the participants was measured throughout the duration of the present investigation, dietary information $24 \mathrm{~h}$ prior to experimental testing sessions was not monitored. Although participants were instructed to maintain similar dietary intakes for the day leading up to each acute training session, muscle glycogen stores leading into training days could be affected by diet. Second, there was no true placebo administered. With no true placebo, comparisons cannot be made between the effects of $\mathrm{CHO}$ and $\mathrm{CON}$ supplementation to no supplement. Another limitation is the

Table 6 Performance during two-foot line jumps

\begin{tabular}{|c|c|c|c|c|c|}
\hline & & Total touches & $15 \mathrm{~g} / \mathrm{h}$ & $30 \mathrm{~g} / \mathrm{h}$ & $60 \mathrm{~g} / \mathrm{h}$ \\
\hline \multirow[t]{3}{*}{$2 \mathrm{ft}$ Line Jumps } & CON & $27.9 \pm 2.1$ & $\begin{array}{l}3.4 \% ;-0.1 \text { to } 2.0(0.39) \\
92.4 \% \text {, likely }(16) \\
p=0.14\end{array}$ & $\begin{array}{l}3.4 \% ;-0.1 \text { to } 2.0(0.39) \\
92.4 \% \text {, likely }(16) \\
p=0.14\end{array}$ & $\begin{array}{l}2.7 \% ;-1.0 \text { to } 2.5(0.25) \\
77.4 \% \text {, likely (65) } \\
p=0.42\end{array}$ \\
\hline & $15 \mathrm{~g} / \mathrm{h}$ & $28.8 \pm 2.7$ & & $\begin{array}{l}-1.3 \% ;-1.3 \text { to } 0.6(0.14) \\
21.1 \% \text {, unlikely }(197) \\
p=0.47\end{array}$ & $\begin{array}{l}-0.7 \% ;-2.1 \text { to } 1.7(0.06) \\
40.4 \% \text {, possibly }(2511) \\
p=0.85\end{array}$ \\
\hline & $30 \mathrm{~g} / \mathrm{h}$ & $28.4 \pm 2.8$ & & & $\begin{array}{l}0.7 \% ;-1.2 \text { to } 1.6(0.06) \\
57.0 \% \text {, possibly }(2194) \\
p=0.80\end{array}$ \\
\hline
\end{tabular}


lack of mechanistic data collection such as blood markers. Although we lacked mechanistic data, results from this study indicate the possibility of performance increments with $\mathrm{CHO}$ supplementation during strength and conditioning training. Future studies in this area should focus on mechanistic data collection to analyze muscle metabolism and markers of muscle damage, to possibly explain the results of this current study.

\section{Conclusions}

The data from this investigation indicate that $\mathrm{CHO}$ supplementation has an increased likelihood to improve performance compared to non- $\mathrm{CHO}$ when completing an acute strength and conditioning protocol. Although there were significant main effects found in relation to DB bench press performance and performance was very likely to increase with $15 \mathrm{~g} / \mathrm{h}$ in overall RT performance and $60 \mathrm{~g} / \mathrm{h}$ in $27-\mathrm{m}$ sprint performance, there were also $\mathrm{RT}$, jumping, and sprinting performance variables that suggested slight beneficial effects. Without measurement of mechanistic data as previously explained, it is difficult to explain the possible mechanisms why one exercise was significantly improved and others were not. Future studies are needed to further investigate the efficacy of $\mathrm{CHO}$ ingestion during strength and conditioning training along with focusing on the effects of $\mathrm{CHO}$ supplementation compared to a true placebo. Overall, the combined results of this study would suggest that $\mathrm{CHO}$ ingestion rates of $15-30 \mathrm{~g} / \mathrm{h}$ with $\sim 500 \mathrm{~mL}$ of fluid will likely lead to the greatest overall performance compared to supplementing only amino acids during acute strength and conditioning training sessions.

\section{Abbreviations \\ 1-RM: One- repetition maximum; ANOVA: Analysis of variance; BB: Barbell; CHO: Carbohydrate; CON: Amino-acid electrolyte control; DB: Dumbbell; RT: Resistance training}

\section{Acknowledgements}

The authors thank the participants for devoting time to this study.

\section{Funding}

Dymatize Enterprises, LLC. provided the supplementation and funding for this study. The authors would like to thank Dymatize for providing funding for this study.

\section{Availability of data and materials}

Data is available upon request by emailing bmk216@msstate.edu.

\begin{abstract}
Authors' contributions
BMK, JWS, BJF, PJF, and MJM assisted in study design, participant recruitment, and data analyses. BMK, JAR, and TJP performed data collection. JWS was responsible for securing research funding. BMK, JWS, and MJM drafted the first version of the manuscript. All authors read and approved the final manuscript.
\end{abstract}

\section{Competing interests}

The authors declare that they have no competing interests.

\section{Consent for publication}

N/A.

\section{Ethics approval and consent to participate}

All participants gave their informed consent before participation in the study. The Mississippi State University Institutional Review Board approved the study on September 24, 2015 and the protocol number assigned was 15-288.

\section{Author details}

'Department of Kinesiology, Mississippi State University, Mississippi State, MS 39762, USA. 'Department of Food Science, Nutrition, and Health Promotion, Mississippi State University, Mississippi State, MS 39762, USA.

Received: 12 August 2016 Accepted: 5 November 2016 Published online: 10 November 2016

References

1. Durell DL, Pujol TJ, Arnes JT. A survey of the scientific data and training methods utilized by collegiate strength and conditioning coaches. J Strength Cond Res. 2003;17:368-73.

2. Robergs RA, Pearson DR, Costill DL, Fink WJ, Pascoe DD, Benedict MA, Lambert CP, Zachweija JJ. Muscle glycogenolysis during differing intensities of weight-resistance exercise. J Appl Physiol. 1991;70:1700-6.

3. Tesch PA, Ploutz-Snyder LL, Yström L, Castro MJ, Dudley GA. Skeletal muscle glycogen loss evoked by resistance exercise. J Strength Cond Res. 1998;12:67-73.

4. Haff GG, Stone MH, Warren BJ, Keith R, Johnson RL, Nieman DC, Williams F, Kirksey KB. The effect of carbohydrate supplementation on multiple sessions and bouts of resistance exercise. J Strength Cond Res. 1999;13:111-7.

5. Haff GG, Schroeder C, Koch AJ, Kuphal KE, Comeau MJ, Potteiger JA. The effects of supplemental carbohydrate ingestion on intermittent isokinetic leg exercise. J Sports Med Phys Fitness. 2001;41:216-22.

6. Lambert CP, Flynn MG, Boone Jr JB, Michaud TJ, Rodriguez-Zayas J. Effects of carbohydrate feeding on multiple-bout resistance exercise. J Strength Cond Res. 1991;5:192-7.

7. Wax B, Brown SP, Webb HE, Kavazis AN. Effects of carbohydrate supplementation on force output and time to exhaustion during static leg contractions superimposed with electromyostimulation. J Strength Cond Res. 2012;26:1717-23.

8. Wax B, Kavazis AN, Brown SP. Effects of supplemental carbohydrate ingestion during superimposed electromyostimulation exercise in elite weightlifters. J Strength Cond Res. 2013;27:3084-90.

9. Conley M, Stone M, Marsit J, O'Bryant HS, Nieman DC, Johnson JL, ButTerworth D, Keith R. Effects of carbohydrate ingestion on resistance exercise. J Strength Cond Res. 1995;9:20.

10. Haff GG, Koch AJ, Potteiger JA, Kuphal KE, Magee LM, Green SB, Jakicic JJ. Carbohydrate supplementation attenuates muscle glycogen loss during acute bouts of resistance exercise. Int J of Sport Nutr Exerc Metab. 2000;10:326-39.

11. Kulik JR, Touchberry CD, Kawamori N, Blumbert PA, Crum AJ, Haff GG. Supplemental carbohydrate ingestion does not improve performance of high-intensity resistance exercise. J Strength Cond Res. 2008;22:1101-7.

12. de Oliveira Quirino EL. da Conceição Rodrigues Gonçalves M, Coutinho de Oliveira CV, Porto dos Santos E, Silva AS. Influence of carbohydrate supplementation during resistance training on concentrations of the hormones cortisol and insulin. Sport Sci Health. 2012;7:93-7.

13. Thyfault JP, Carper MJ, Richmond SR, Hulver MW, Potteiger JA. Effects of liquid carbohydrate ingestion on markers of anabolism following high-intensity resistance exercise. J Strength Cond Res. 2004;18:174-9.

14. Bird SP, Tarpenning KM, Marino FE. Liquid carbohydrate/essential amino acid ingestion during a short-term bout of resistance exercise suppresses myofibrillar protein degradation. Metabolism. 2006;55:570-7.

15. Koenig CA, Benardot D, Cody M, Thompson WR. Comparison of creatine monohydrate and carbohydrate supplementation on repeated jump height performance. J Strength Cond Res. 2008;22:1081-6.

16. Winnick JJ, Davis JM, Welsh RS, Carmichael MD, Murphy EA, Blackmon JA. Carbohydrate feedings during team sport exercise preserve physical and cns function. Med Sci Sports Exerc. 2005;37:306-15.

17. Baker LB, Dougherty KA, Chow M, Kenney WL. Progressive dehydration causes a progressive decline in basketball skill performance. Med Sci Sports Exerc. 2007;39:1114-23.

18. Dougherty KA, Baker LB, Chow M, Kenney WL. Two percent dehydration impairs and six percent carbohydrate drink improves boys basketball skills. Med Sci Sports Exerc. 2006;38:1650-8. 
19. Welsh RS, Davis JM, Burke JR, Williams HG. Carbohydrates and physical/ mental performance during intermittent exercise to fatigue. Med Sci Sports Exerc. 2002;34:723-31.

20. Faude $\mathrm{O}$, Koch $\mathrm{T}$, Meyer $\mathrm{T}$. Straight sprinting is the most frequent action in goal situations in professional football. J Sports Sci. 2012;30:625-31.

21. McGee KJ, Burkett LN. The national football league combine: A reliable predictor of draft status? J Strength Cond Res. 2003;17:6-11.

22. Sierer SP, Battaglini CL, Mihalik JP, Shields EW, Tomasini NT. The national football league combine: Performance differences between drafted and nondrafted players entering the 2004 and 2005 drafts. J Strength Cond Res. 2008;22:6-12

23. Ali A, Williams C, Nicholas CW, Foskett A. The influence of carbohydrateelectrolyte ingestion on soccer skill performance. Med Sci Sports Exerc. 2007;39:1969-76.

24. Gant N, Leiper JB, Williams C. Gastric emptying of fluids during variableintensity running in the heat. Int J of Sport Nutr Exerc Metab. 2007;17:270-83.

25. Smith JW, Zachwieja JJ, Peronnet F, Passe DH, Massicotte D, Lavoie C, Pascoe DD. Fuel selection and cycling endurance performance with ingestion of [13c]glucose: Evidence for a carbohydrate dose response. J Appl Physiol. 2010;108:1520-9.

26. Haff GG, Triplett NT. Essentials of strength training and conditioning 4th ed. Champaign: Human Kinetics; 2015.

27. Brzycki M. Strength testing- Predicting a one-rep max from reps-to-fatigue. J Phys Ed Rec \& Dance. 1993:64:88-90.

28. Hopkins WG, Marshall SW, Batterham AM, Hanin J. Progressive statistics for studies in sports medicine and exercise science. Med Sci Sports Exerc. 2009;41:3-13.

29. Hopkins WG, Hawley JA, Burke LM. Design and analysis of research on sport performance enhancement. Med Sci Sports Exerc. 1999;31:472-85.

30. Hopkins WG. A spreadsheet for deriving a confidence interval, mechanistic inference and clinical inference from a p value. Sportscience. 2007;11:16-21.

31. Morrow JR, Wong SP. Forming inferences about some intraclass correlation coefficients. Psychol Methods. 1996;1:30-46.

32. Pitkänen HT, Oja SS, Rusko H, Nummela A, Komi PV, Saransaari P, Takala T, Mero AA. Leucine supplementation does not enhance acute strength or running performance but affects serum amino acid concentration. Amino Acids. 2003;25:85-94

33. MacDougall JD, Ray S, Sale DG, McCartney N, Lee P, Garner S. Muscle substrate utilization and lactate production. Can J Appl Physiol. 1999:24:209-15

34. Pascoe DD, Costill DL, Fink WJ, Robergs RA, Zachwieja JJ. Glycogen resynthesis in skeletal muscle following resistive exercise. Med Sci Sports Exerc. 1993:25:349-54.

35. Tesch PA, Colliander EB, Kaiser P. Muscle metabolism during intense, heavy-resistance exercise. Eur J Appl Physiol Occup Physiol. 1986;55:362-6.

36. Jeukendrup $A E$, Chambers ES. Oral carbohydrate sensing and exercise performance. Curr Opin Clin Nutr Metab Care. 2010;13:447-51.

37. Carter JM, Jeukendrup AE, Jones DA. The effect of carbohydrate mouth rinse on 1-h cycle time trial performance. Med Sci Sports Exerc. 2004;36:2107-11.

38. Chambers ES, Bridge MW, Jones DA. Carbohydrate sensing in the human mouth: Effects on exercise performance and brain activity. J Physiol. 2009;587:1779-94.

39. Pottier A, Bouckaert J, Gilis W, Roels T, Derave W. Mouth rinse but not ingestion of a carbohydrate solution improves 1-h cycle time trial performance. Scand J Med Sci Sports. 2010;20:105-11.

40. Whitham M, McKinney J. Effect of a carbohydrate mouthwash on running time-trial performance. J Sports Sci. 2007;25:1385-92.

41. Dorling $J L$, Earnest CP. Effect of carbohydrate mouth rinsing on multiple sprint performance. J Int Soc Sports Nutr. 2013;10:41.

42. Painelli VS, Roschel H, Gualano B, Del-Favero S, Benatti FB, Ugrinowitsch C, Tricoli $\mathrm{V}$, Lancha Jr AH. The effect of carbohydrate mouth rinse on maximal strength and strength endurance. Eur J Appl Physiol. 2011;111:2381-6.

43. Clarke ND, Kornilios E, Richardson DL. Carbohydrate and caffeine mouth rinse do not affect maximum strength and muscular endurance performance. J Strength Cond Res. 2015;29:2926-31.
44. Smith JW, Pascoe DD, Passe DH, Ruby BC, Stewart LK, Baker LB, Zachwiega JJ. Curvilinear dose-response relationship of carbohydrate (0-120 g.h(-1)) and performance. Med Sci Sports Exerc. 2013;45:336-41.

\section{Submit your next manuscript to BioMed Central and we will help you at every step:}

- We accept pre-submission inquiries

- Our selector tool helps you to find the most relevant journal

- We provide round the clock customer support

- Convenient online submission

- Thorough peer review

- Inclusion in PubMed and all major indexing services

- Maximum visibility for your research

Submit your manuscript at www.biomedcentral.com/submit

) Biomed Central 